\title{
The Role of Montelukast in Traumatic Brain Injury and Brain Ischemia
}

\author{
Nida Fatima ${ }^{1 *}$, Ashfaq Shuaib ${ }^{2}$ and Maher Saqqur ${ }^{3}$ \\ ${ }^{1}$ Department of Neurosurgery, Stanford University School of Medicine, USA \\ ${ }^{2}$ Department of Neurology, University of Alberta, Canada
}

Submission: May 10,2019; Published: May 28, 2019

*Corresponding author: Nida Fatima, Department of Neurosurgery, Stanford University School of Medicine, USA

\begin{abstract}
Introduction: Montelukast has a fundamental role in the management of respiratory disorders including asthma and allergic rhinitis. We reviewed literature to determine the role of Montelukast in Traumatic Brain Injury and Brain Ischemia.

Methods: Articles reported from 1950 to present and identified through PubMed, Cochrane, and Google Scholar were searched on the use of Montelukast in traumatic brain injury and ischemia.

Results: Montelukast is a Cysteinyl leukotriene receptor-1 antagonist. Cysteinyl leukotriene receptors have a dynamic biphasic response to appear on the surface of brain, as it increases 3-24 hours and then 7 days after brain trauma and ischemia. Montelukast plays an important role in neuroprotection and anti-apoptotic pathway by antagonizing these receptors. Its unique mechanism of action is evident by halting lipid peroxidation, neutrophil accumulation and pro inflammatory cytokine release, thereby, preventing metabolic crisis and stabilizing the blood brain barrier. However, almost all these studies are carried out in experimental model. Therefore, there is an urgent need to confirm the use of this drug in patients with TBI and ischemia.

Conclusion: In recent years, in addition to Montelukast effects in respiratory disorders, several studies have presented evidence suggesting its potential to have a neuroprotective effect in traumatic brain injury and ischemia. Therefore, further clinical trials might help in determining the efficacy, safety and role of Montelukast in traumatic brain injury and ischemia.
\end{abstract}

Keywords: Montelukast; Traumatic brain injury; Ischemia; Intracranial hypertension; Cysteinyl Leukotriene receptor

Abbreviations: TBI: Traumatic Brain Injury; ICP: Intracranial Pressure; CPP: Cerebral Perfusion Pressure

\section{Introduction}

Traumatic Brain Injury (TBI) is a 'silent epidemic' and the leading cause of mortality and morbidity worldwide. Due to significant external impact to the brain, there is alteration in the normal cerebrovascular physiology. This leads to increase in Intracranial Pressure (ICP), reduction in Cerebral Perfusion Pressure (CPP), and ultimately brain edema [1,2]. There exists controversial literature regarding the time course of disruption of Blood Brain Barrier (BBB) following TBI and ischemia; with some studies suggesting it to be short-lived [3] while other suggest it to be following a biphasic course, with 3-6 hours as early-phase disruption followed by further BBB disruption in 1-3 days after injury [4]. Recent therapeutic strategies focus upon stabilization of BBB, thus decreasing intracellular brain edema.

Montelukast is a Cysteinyl-Leukotriene Receptor-1 Inhibitor. It has a documented role in allergic rhinitis and asthma, however, there exist literature for its role in treating neurological conditions like Alzheimer's, Multiple Sclerosis, Epilepsy [3-9]. In addition, preclinical studies suggest that it might be useful in TBI by stabilizing BBB4. Its unique mechanism of action is evident by halting the inflammatory cascade following TBI that involves lipid peroxidation, neutrophil accumulation and pro inflammatory cytokine release [9]. Thus, it has a role in neuroprotection and anti-apoptotic pathway. The use of Montelukast for the management of BBB stabilization and reduction of brain edema secondary to trauma and ischemia is largely the result of experimental evidences and small clinical trials. Our review article is the first to determine the efficacy of Montelukast in Traumatic Brain Injury and brain ischemia.

\section{Methods}

We applied stringent inclusion criteria, selecting articles (experimental or non-experimental) describing role of 
Montelukast in neurological conditions especially in reducing brain edema and stabilizing the blood brain barrier. Articles on role of Montelukast in non-neurological symptoms (asthma, allergic rhinitis, gastrointestinal tract) were excluded. We used the following MeSH headings Montelukast or traumatic brain injury or brain ischemia. We did not define any limitation in language. Articles published between 1950 and the present were searched. The following databases were reviewed: Cochrane Library, PubMed and Google Scholar. This has been indicated in the Figure 1 To avoid publication bias, we reviewed abstracts from European and American traumatic brain injury meetings, looking at the unpublished articles on Montelukast in TBI and ischemia.

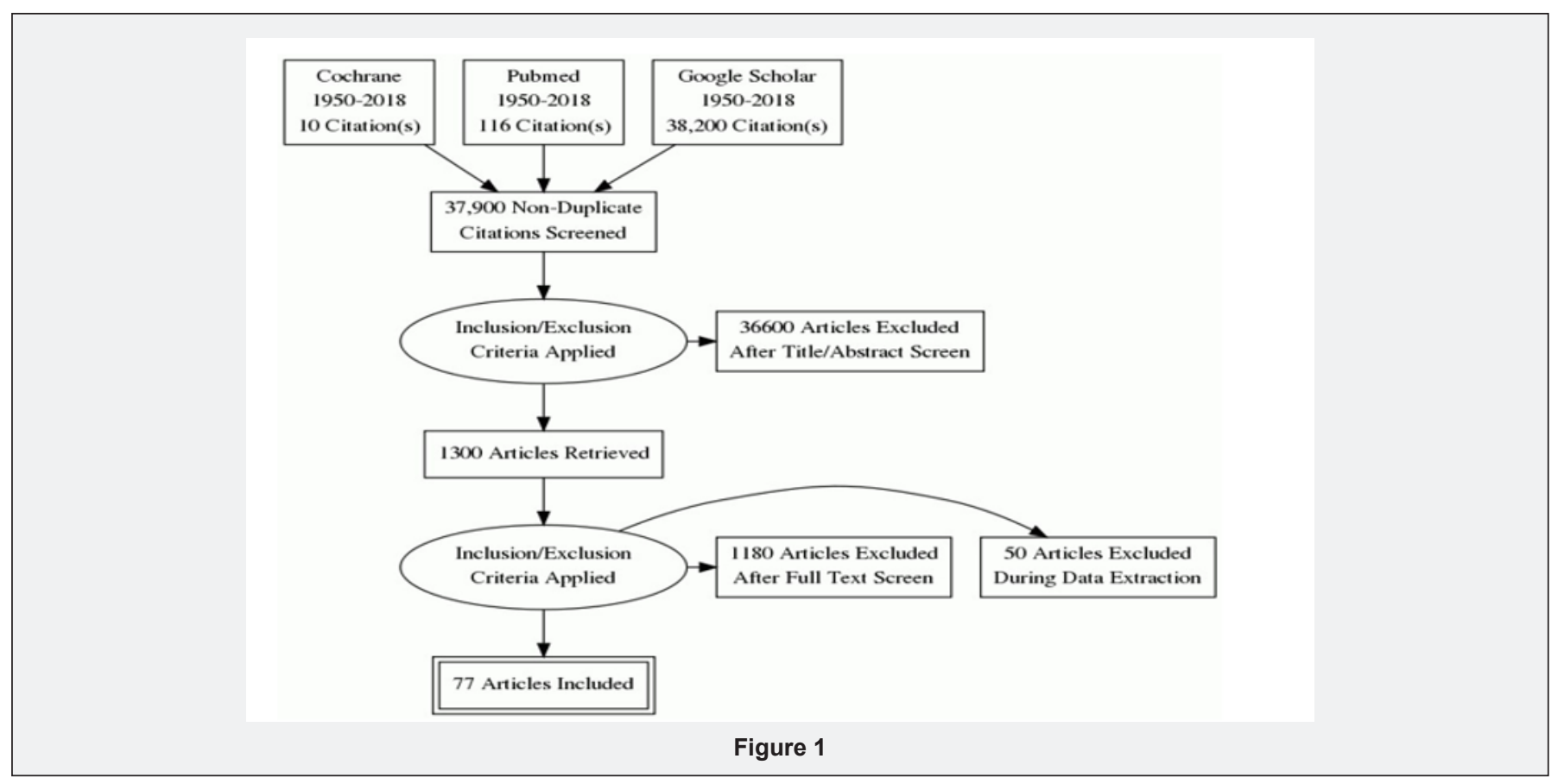

\section{Study selection and data extraction}

Primary research question: Does Montelukast play role in Traumatic Brain Injury and brain ischemia. Therefore, we reviewed all the articles including pre-clinical trials using Montelukast in TBI and ischemia, and determined the dose, timing and clinical outcome. 2 articles were included in which the ischemia was induced by occlusion of middle cerebral artery leading to brain edema; thus, to determine the role of Montelukast in reducing brain edema. The reviewer was not blind to the author's name and institutions, journals of publication, or study results.

\section{Results}

After primary impact to the brain (trauma or ischemia), secondary brain damage occurs due to multiple factors including the activation of inflammatory pathway $[10,11]$. Various Cysteinyl leukotrienes (LTC4, LTD4, LTE4) are produced [12-14] which causes release of reactive oxygen species [15] that are involved in phospholipid breakdown [16], ultimately increasing the membrane permeability [17]. This lay the foundation of disruption of blood brain barrier. Primary BBB damage $[18,19]$ occurs due to shearing of the endothelium of blood vessels as a result of direct head trauma. However, abnormal brain activity, inflammation, astrocyte dysfunction and metabolic disturbances in response to brain injury and ischemia leads to Secondary BBB disruption [20].

During several pathological conditions (ischemia [20-22] traumatic brain injury [23]), there is increase expression of CysLTRs on the surface of brain. CysLTR-1 expression is localized in microvascular endothelial cells [24], in glial cells (namely astrocytes and microglia [25-27]) and in various other kinds of neuronal cells $[21,26]$. On the other hand, the CysLTR-2 is expressed in many regions of human brain such as hypothalamus, thalamus, putamen, pituitary, and medulla [28], astrocytes [25] and vascular smooth muscle cells [23]. It is also observed in neurons and glial-appearing cells [23] after brain trauma and in brain tumors. Microglial cells play a neuroprotective role [29,30] but over activation causes release of inflammatory mediators (cytokines and nitric oxide) [31,32] leading to detrimental effects [33,34] including neuronal injury [35-39]. Montelukast has CysLTR-1 receptor dependent and independent effects.

Montelukast dependent effect occurs by directly acting upon its receptor (CysLTR-1) and decreasing inflammation [20,40,41] and astrocyte proliferation [27,42]. It has several independent effects of its receptor including indirectly inhibiting GPR17 [4349] and $P 2 Y$ receptor [50-52] thus reducing neuronal injury after ischemia [53-56]. It is found to reverse the cognitive deficit in Alzheimer's disease by inhibiting the inflammatory and apoptotic 
response to $A \beta 1-4[6,25,57,58]$. In addition, in Multiple sclerosis 7 and Epilepsy $[8,9,59]$ it inhibits the chemotaxis of inflammatory mediators and leukocyte infiltration, thus preventing against demyelination and seizures $[60,61]$ respectively. Montelukast is extensively metabolized.

In vitro studies using human liver microsomes indicated the cytochromes P450 3A4 and 2C9 involved in the metabolism of Montelukast. The plasma clearance of Montelukast averages $45 \mathrm{ml} / \mathrm{min}$ in healthy adults. The mean plasma half-life of Montelukast ranged from 2.7 to 5.5 hours in healthy young adults [62]. The patients with memory loss and dementia showed improvement in memory function using $20 \mathrm{mg}$ orally upon arising and then 20mg every 2-3 hours for a total of 4 doses [63].

Common side effects associated with Montelukast include diarrhea, nausea, vomiting, mild rashes, asymptomatic elevation in liver enzymes, and fever. Uncommon side effects include fatigue, malaise, behavioral changes, paresthesia and seizures, muscle cramps, and nosebleed. Rare but serious side effects include severe behavioral changes, angioedema, erythema multiforme, and liver problems [64]. Although clinical trials revealed an increased risk of insomnia, post marketing surveillance showed that this drug is associated with increased risk of suicidal behavior and other side effect such as agitation, aggression, anxiousness, dream abnormalities and hallucinations, depression, irritability, restlessness, and tremor [64].

\section{Discussion}

Brain was considered to be immunologically privileged site, butseveral literatures exist against this notion. After TBI and brain ischemia, the inflammatory response begins within hours and last several days to weeks [65]. As a result of disruption of BBB, there is transmigration of leukocytes, which results in activation of the resident cells of CNS (such as microglia and astrocytes) to possess the immunological function. This infiltration of immune cells and activated resident cells, subsequently leads to increased intrathecal production of cytokines [65]. There exists a vicious cycle as release of chemokines, adhesion molecules, and proinflammatory cytokines released from activated microglia [66], further mediate the migration of peripheral immune cells and activation of resident CNS cells, which ultimately contribute to an overall increase in the blood brain permeability [67]. In response to activation of glial cells, modulation of synaptic transmission and plasticity occurs, [68,69] which ultimately leads to seizures due to neuronal network re organization, hyper synchronicity and hyper excitability [70].

Excessive inflammatory response is associated with the poor clinical outcome; therefore, prevention of inflammation is prudent therapeutic strategy. Besides, the protection against post traumatic epilepsy could be obtained by decreasing the activation of astrocytes. Cysteinyl leukotrienes receptors are increased on the surface of neurons and glial producing cells (astrocytes and glial cells) following brain trauma and ischemia. Neuroprotective and anti-apoptotic role of Montelukast is evident by inhibiting the lipid peroxidation, neutrophil accumulation and pro inflammatory cytokine release [71], eventually reducing the blood brain permeability [72]. Stabilization of the BBB after TBI and ischemia could be a promising strategy to limit neuronal inflammation, secondary brain damage and acute neurodegeneration [73].

Cysteinyl leukotriene receptors has a dynamic biphasic response to appear on the surface of brain, as it increases 3-24 hours and then 7 days after brain trauma and ischemia [32]. In a fluid percussion model of traumatic brain injury to the rats [74], the levels of cysteine leukotrienes were elevated after fluid percussion injury with a maximal formation 1 hour after injury. Using immunohistochemical analyses, they found increased expression of CysLT1 on microvascular endothelial cells along with increased expression neurons and glialappearing cells in gray and white matter after traumatic brain injury and brain ischemia [24]. Montelukast has a dose and timedependent neuroprotective effect [75]. This was determined in an experimental model in mice by occluding the Middle Cerebral Artery (MCAO). Montelukast was injected intraperitoneally either as multiple doses (once a day for 3 days and 30 mins before MCAO) or as a single dose (at $30 \mathrm{~min}$ before, $30 \mathrm{~min}$ after, or 1 hour after MCAO). It was found that Montelukast single dose given within 30 minutes of ischemia reduced the brain edema and infarct volume, however, there was no effect on neurological deficit. Similarly, in another experiment [25] it was found that Montelukast $(0.1 \mathrm{mg} / \mathrm{kg})$ attenuated behavioral dysfunction, brain infarct volume, brain atrophy and neuron loss in mice after transient focal cerebral ischemia induced by Middle Cerebral Artery Occlusion. Therefore, Montelukast decreases the intracellular edema and hence, reduces the intracranial pressure as evident by the experimental model. Montelukast down regulates the migration of LTD4-induced astrocyte migration by inhibiting TGF-beta 1, thus prevent inflammatory response and abnormal synaptic activity 39 . Thus, it can help in preventing the seizures activity.

Our study has several limitations. Firstly, there is a possibility of selection and publication bias since one reviewer carried out this process. Therefore, he might be influenced by positive trials only. However, we tried to limit such bias by reviewing all articles including the unpublished literature as well. Second, almost all articles were experimental models conducted on animals, therefore, it makes it difficult to imply on human beings as well. Finally, the results cannot be generalized to all forms of traumatic brain injury since the article limited to severe traumatic brain injury.

\section{Conclusion}

Montelukast as Cysteinyl leukotrienes Receptor-1 antagonist has a clear role in the pathophysiological conditions such as 


\section{Open Access Journal of Neurology \& Neurosurgery}

asthma, allergic rhinitis and other nasal allergies. Besides, its role has been implicated in a number of inflammatory conditions including cardiovascular and gastrointestinal diseases [76] However, its role in the treatment of cerebral disorders is still evolving [5-8]. With the experimental clinical trials, there is consistent reduction in the blood brain permeability and inflammatory responses following the administration of Montelukast without any reported adverse events.

The mechanism of action of Montelukast in reducing the BBB and ICP is not fully understood. But it seems that it's due to its effect on the inflammatory mediators that protects the neurons and stabilizes the blood brain barrier by acting upon the endothelial cells. Although there is lack of convincing data regarding its use in traumatic brain injury, but it appears that Montelukast will attenuate the secondary brain damage by inhibiting the inflammatory mediators. Data regarding the best route of administration is also lacking although the oral route would appear to be ideal [77]. Therefore, further clinical studies in form of Randomized Clinical Trials are suggested to determine the efficacy, safety and role of Montelukast in TBI.

\section{Funding}

This research received no specific grant from any funding agency in the public, commercial, or not-for-profit sectors.

\section{Contributor Ship}

Maher Saqqur and Ashfaq Shuaib.

\section{References}

1. Tsai TH, Huang TY, Kung SS, Su YF, Hwan SL, et al. (2013) Intraoperative intracranial pressure and cerebral perfusion pressure for predicting surgical outcome in severe traumatic brain injury. Kaohsiung J Med Sci 29(10): 540-546.

2. Tucker B, Aston J, Dines M, Caraman E, Yacyshyn M, et al. (2017) Early Brain edema is a predictor of in-hospital mortality in Traumatic Brain Injury. J Emerg Med 53(1): 18-29.

3. Barzo P, Marmarou A, Fatouros P, Corwin F, Dunbar J (1996) Magnetic resonance imaging-monitored acute blood brain barrier changes in the experimental traumatic brain injury. J Neurosurg 85(6): 13-21.

4. Baldwin SA, Fugaccia I, Brown DR, Brown LV, Scheff SW (1996) Blood brain barrier breach following cortical contusion in the rat. J Neurosurg 85(3): 476-481.

5. Marschallinger J, Schäffner, Klein B, Gelfert R, Rivera FJ, et al. (2015) Structural and functional rejuvenation of the aged brain by an approved anti-asthmatic drug. Nature Communications 6: 8466.

6. Uz T, Pesold C, Longone P, Manev H (1998) Aging-associated upregulation of neuronal 5-lipoxygenase expression: putative role in neuronal vulnerability. FASEB J 12(6): 439-449.

7. Wang L, Du C, Lv J, Wei W, Cui Y, et al. (2011) Antiasthmatic drugs targeting the Cysteinyl leukotriene receptor 1 alleviate central nervous system inflammatory cell infiltration and pathogenesis of experimental autoimmune encephalomyelitis. J Immunol 187(5): 2336-2345.

8. Simmet T, Tippler B (1990) Cysteinyl-leukotriene production during limbic seizures triggered by kainic acid. Brain Res 515(1-2): 79-86.

9. Kim HC, Jhoo WK, Bing G, Shin EJ, Wie MB, et al. (2000) Phenidone prevents kainate-induced neurotoxicity via antioxidant mechanisms. Brain Research 874(1): 15-23.
10. Phillis JW, O Regan MH (2003) The role of phospholipases, cyclooxygenases, and lipoxygenases in cerebral ischemic traumatic injuries. Crit Rev Neurobiol 15(1): 61- 90.

11. Leslie CC (2004) Regulation of the specific release of arachidonic acid by phospholipase A2. Prostaglandins Leukot Essent Fatty Acids 70(4): 373-376.

12. Rouzer CA, Matsumoto T, Shimizu T, Samuelsson B (1986) The human leukocyte 5-lipoxygenase: enzyme purification, multi-component regulatory system, and LTA4 synthase activity. Adv Prostaglandin Thromboxane Leukot Res 16: 3-16.

13. Haeggstrom JZ (2004) Leukotriene A4 hydrolase aminopeptidase, the gatekeeper of chemotactic leukotriene B4 biosynthesis. J Biol Chem 279(49): 50639-50642.

14. Lam BK (2003) Leukotriene C4 synthase. Prostaglandins Leukot Essent Fatty Acids 69(2-3): 111-116.

15.Erşahin M, Çevik Ö, Akakın D, Şener A, Özbay L, et al. (2012) Montelukast inhibits caspase-3 activity and ameliorates oxidative damage in the spinal cord and urinary bladder of rats with spinal cord injury. Prostaglandins other Lipid Mediat 99(3-4): 131-139.

16. Lewén A, Hillered L (1998) Involvement of reactive oxygen species in membrane phospholipid breakdown and energy perturbation after traumatic brain injury in the rat. J Neurotrauma 15(7): 521-530.

17. Hall ED, Andrus PK, Yonkers PA (1993) Brain hydroxyl radical generation in acute experimental head injury. J Neurochem 60(2): 588-594.

18. Ehrlich P (1885) Oxygen need by the organism: analytical study using color. Hirschwald 8: 167.

19. Rodríguez-Baeza A, Reina-de la Torre F, Poca A, Martí M, Garnacho A (2003) Morphological features in human cortical brain microvessels after head injury: a three-dimensional and immunocytochemical study. Anat Rec A Discov Mol Cell Evol Biol 273(1): 583-593.

20. Shlosberg D, Benifla M, Kaufer D, Friedman A (2010) Blood-brain barrier breakdown as a therapeutic target in Traumatic brain injury. Nat Rev Neurol 6(7): 393- 403.

21. Fang SH, Wei EQ, Zhou Y, Wang ML, Zhang WP, et al. (2006) Increased expression of cysteinyl leukotriene receptor- 1 in the brain mediates neuronal damage and astrogliosis after focal cerebral ischemia in rats. Neuroscience 140(3): 969-979.

22. Fang SH, Zhou Y, Chu LS, Zhang WP, Wang ML (2007) Spatio-temporal expression of cysteinyl leukotriene receptor-2 mRNA in rat brain after focal cerebral ischemia. Neuroscience Letters 412(1): 78-83.

23. Hu H, Chen G, Zhang JM, Zhang WP, Zhang L, et al. (2005) Distribution of cysteinyl leukotriene receptor 2 in human traumatic brain injury and brain tumors. Acta Pharmacol Sin 26(6): 685-690.

24. Zhang WP, Hu H, Zhang L, Ding W, Yao HT, et al. (2004) Expression of cysteinyl leukotriene receptor 1 in human traumatic brain injury and brain tumors. Neuroscience Letters 363(3): 247-251.

25. Zhao CZ, Zhao B, Zhang XY, Huang XQ Shi WZ, et al. (2011) Cysteinyl leukotriene receptor 2 is spatiotemporally involved in neuron injury, astrocytosis and microgliosis after focal cerebral ischemia in rats. Neuroscience 189: 1-11.

26. Yu SY, Zhang XY, Wang XR, Xu DM, Chen L, et al. (2014) Cysteinyl leukotriene receptor 1 mediates LTD4-induced activation of mouse microglial cells in vitro. Acta Pharmacol Sinica 35(1): 33-40.

27. Huang XJ, Zhang WP, Li CT, Shi WZ, Fang SH, et al. (2008) Activation of CysLT receptors induces astrocyte proliferation and death after oxygen-glucose deprivation. Glia 56(1): 27-37.

28. Heise CE, O Dowd BF, Figueroa DJ, Sawyer N, Nguyen T, et al. (2000) Characterization of the human cysteinyl leukotriene 2 receptor. The Journal of Biological Chemistry 275(39): 30531-30536. 


\section{Open Access Journal of Neurology \& Neurosurgery}

29. Hanisch UK, Kettenmann H (2007) Microglia: active sensor and versatile effector cells in the normal and pathologic brain, Nature Neuroscience 10(11): 1387-1394.

30. Liu Z, Chopp M (2016) Astrocytes, therapeutic targets for neuroprotection and neurorestoration in ischemic stroke, Progress in Neurobiology 144: 103-120.

31. Henn A, Lund S, Hedtjärn M, Schrattenholz A, Pörzgen P, et al. (2009) The suitability of BV2 cells as alternative model system for primary microglia cultures or for animal experiments examining brain inflammation. ALTEX 26(2): 83-94.

32. Zhou Y, Wei EQ Fang SH, Chu LS, Wang ML, et al. (2006) Spatiotemporal properties of 5-lipoxygenase expression and activation in the brain after focal cerebral ischemia in rats. Life Sciences 79(17): $1645-1656$

33. RM Ransohoff, Perry VH (2009) Microglial physiology: unique stimuli, specialized responses. Annual Rev Immunol 27: 119-145.

34. Graeber MB, Streit WJ (2010) Microglia: biology and pathology. Acta Neuropathol 119(1): 89-105.

35. Katayama T, Sakaguchi E, Komatsu Y, Oguma T, Uehara T, et al. (2010) Sustained activation of ERK signaling in astrocytes is critica for neuronal injury induced monocyte chemoattractant protein-1 production in rat corticostriatal slice cultures. The Eur J Neurosci 31(8): 1359-1367.

36. Sullivan SM, Björkman ST, Miller SM, Colditz PB, Pow DV (2010) Structural remodeling of gray matter astrocytes in the neonatal pig brain after hypoxia ischemia. Glia 58(2): 181-194.

37. Qu Y, Duan Z, Zhao F, Wei D, Zhang J, et al. (2011) Telomerase reverse transcriptase upregulation attenuates astrocyte proliferation and pro- motes neuronal survival in the hypoxic-ischemic rat brain. Stroke 42(12): 3542-3550.

38. Pekny M, Pekna M (2014) Astrocyte reactivity and reactive astrogliosis: costs and benefits. Physiol Rev 94(4): 1077-1098.

39. Huang XQ, Zhang XY, Wang XR, Yu SY, Fang SH, et al. (2012) Transforming growth factor $\beta 1$-inducedastrocyte migration is mediated in part by activating 5-lipoxygenase and cysteinyl leukotriene receptor 1 . J Neuroinflammation 9: 134.

40. Zhang WP, Wei EQ Mei RH, Zhu CY, Zhao MH (2002) Neuroprotective effect of ONO-1078, a leukotriene receptor antagonist, on focal cerebral ischemia in rats. Acta Pharmacol Sin 23(10): 871-877.

41. Chu LS, Fang SH, Zhou Y, Yu GL, Wang ML, et al. (2007) Minocycline inhibits 5-lipoxygenase activation and brain inflammation after focal cerebral ischemia in rats. Acta Pharmacol Sin 28(6): 763-772.

42. Yu GL, Wei EQ, Wang ML, Zhang WP, Zhang SH, et al. (2005) Pranlukast, a cysteinyl leukotriene receptor- 1 antagonist, protects against chronic ischemic brain injury and inhibits the glial scar formation in mice. Brain Res 1053(1-2): 116-125.

43. Tintinger GR, Feldman C, Theron AJ, Anderson R (2010) Montelukast: more than a cysteinyl leukotriene receptor antagonist? Scientific World Journal 10: 2403- 2413.

44. Tanaka Y, Tanaka R, Liu M, Hattori N, Urabe T, et al. (2010) Cilostazol attenuates ischemic brain injury and enhances neurogenesis in the subventricular zone of adult mice after transient focal cerebral ischemia. Neuroscience 171(4): 1367-1376.

45. Schaal SM, Garg MS, Ghosh M, Lovera L, Lopez M, et al. (2012) The therapeutic profile of rolipram, PDE target and mechanism of action as a neuroprotectant following spinal cord injury. PloS One 7(9): e43634.

46. Ciana P, Fumagalli M, Trincavelli ML, Verderio C, Rosa P, et al. (2006) The orphan receptor GPR17 dentified as a new dual uracil nucleotides/ cysteinyl-leukotrienes receptor. The EMBO Journal 25(19): 4615-4627.
47. Maekawa A, Balestrieri B, Austen KF, Kanaoka Y (2009) GPR17 is a negative regulator of the cysteinyl leukotriene 1 receptor response to leukotriene D4, Proceedings of the National Academy of Sciences 106(28): 11685-11690

48. Maekawa A, Xing W, Austen KF, Kanaoka Y (2010) GPR17 regulates immune pulmonary inflammation induced by house dust mites. Immunol 185(3): 1846-1854.

49. Lecca D, Trincavelli ML, Gelosa P, Sironi L, Ciana P, et al. (2008) The recently identified P2Y-like receptor GPR17 is a sensor of brain damage and a new target for brain repair. PloS One 3: 10.

50. Zhao B, Zhao CZ, Zhang XY, Huang XQ Shi WZ, et al. (2012) The new P2Y-like receptor $G$ protein coupled receptor 17 mediates acute neuronal injury and late microgliosis after focal cerebral ischemia in rats. Neuroscience 202: 42-57.

51. Muthuraman A, Sood S (2010) Antisecretory, antioxidative and antiapoptotic effects of montelukast on pyloric ligation and water immersion stress induced peptic ulcer in rat. Prostaglandins, Leukot Essent Fat Acids 83(1): 55-60.

52. Coskun AK, Yigiter M, Oral A, Odabasoglu F, Halici Z, et al. (2011) The effects of Montelukast on antioxidant enzymes and proinflammatory cytokines on the heart, liver, lungs, and kidneys in a rat model of cecal ligation and puncture-induced sepsis. Scientific World Journal 11: 1341-1356.

53. Mohamadin AM, Elberry AA, Elkablawy MA, Gawad HS, Al-Abbasi FA (2011) Montelukast, a leukotriene receptor antagonist abrogates lipopolysaccharide-induced toxicity and oxidative stress in rat liver. Pathophysiology 18(3): 235-242.

54. Lau WK, Chow AW, Au SC, Ko WH (2011) Differential inhibitory effects of CysLT1 receptor antagonists on P2Y6 receptor-mediated signaling and ion transport in human bronchial epithelia. PloS One 6(7): e22363.

55. Mamedova L, Capra V, Accomazzo MR, Gao ZG, Ferrario S, et al (2005) CysLT1 leukotriene receptor antagonists inhibit the effects of nucleotides acting at P2Y receptors. Biochemical Pharmacology 71(12): $115-125$.

56. Pugliese AM, Trincavelli ML, Lecca D, Coppi E, Fumagalli M, et al. (2009) Functional characterization of two isoforms of the P2Y-like receptor GPR17: [35S] GTP S binding and electrophysiological studies in 1321N1 cells. Am J Physiol Cell Physiol 297(4): C1028- C1040.

57. Lai J, Hu M, Wang H, Hu M, Long Y, et al. (2014) Montelukast targeting the cysteinyl leukotriene receptor 1 ameliorates $A \beta 1-42$ - induced memory impairment and neuroinflammatory and apoptotic responses in mice. Neuropharmacology 79: 707-714.

58. Tang SS, Ji M, Chen L, Mei Hu, Yan Long, et al. (2014) Protective effect of pranlukast on $A \beta$ 1-42- induced cognitive deficits associated with downregulation of cysteinyl leukotriene receptor 1 . The International Journal of Neuropsychopharmacology 17(4): 581-592.

59. Baran H, Vass K, Lassmann H, Hornykiewicz O (1994) The cyclooxygenase and lipoxygenase inhibitor BW755C protects rats against kainic acid induced seizures and neurotoxicity. Brain Research 646(2): 201-206.

60. Rehni AK, Singh TG (2011) Modulation of leukotriene D4 attenuates the development of seizures in mice. Prostaglandins, Leukotrienes, and Essential Fatty Acids 85(2): 97-106.

61. Lenz QF, Arroyo DS, Temp FR, Poersch AB, Masson CJ, et al. (2014) Cysteinyl leukotriene receptor (CysLT) antagonists decrease pentylenetetrazol- induced seizures and blood-brain barrier dysfunction. Neuroscience 277: 859-871.

62.https: / / www.accessdata.fda.gov/drugsatfda_docs / nda/2014/1255570rig1s000TOC.cfm 


\section{Open Access Journal of Neurology \& Neurosurgery}

63. Rozin SI (2017) Case Series Using Montelukast in Patients with Memory Loss and Dementia. Open Neurology Journal 11: 7-10.

64. (2009) Updated Information on Leukotriene Inhibitors: Montelukast (marketed as Singulair), Zafirlukast (marketed as Accolate), and Zileuton (marketed as Zyflo and Zyflo CR). Food and Drug Administration.

65. Morganti-Kossmann MC, Satgunaseelan L, Bye N, Kossmann T (2007) Modulation of immune response by head injury. Injury 38(12): 1392 1400 .

66. Allan SM, Rothwell NJ (2001) Cytokines and acute neurodegeneration Nat Rev Neurosci 2(10): 734-744.

67. Lucas SM, Rothwell NJ, Gibson RM (2006) The role of inflammation in CNS injury and disease. Br J Pharmacol 147 (1): S232-S340.

68. Filosa A, Paixão S, Honsek SD, Carmona MA, Becker L, et al. (2009) Neuron-glia communication via EphA4/ephrin-A3 modulates LTP through glial glutamate transport. Nat Neurosci 12(10):1285-1292.

69. Henneberger C, Papouin T, Oliet SH, Rusakov DA (2010) Long-term potentiation depends on release of D-serine from astrocytes. Nature 463(7278): 232-236.

70. David Y, Cacheaux LP, Ivens S, Lapilover E, Heinemann U, et al. (2009) Astrocytic dysfunction in epileptogenesis: consequence of altered potassium and glutamate homeostasis? J Neurosci 29(34): 1058810599.
71. Theron AJ, Steel HC, Tintinger GR, Gravett CM, Anderson R, et al. (2014) Cysteinyl Leukotriene Receptor-1 Antagonists as Modulators of Innate Immune Cell Function. J Immunol Res 2014: 608930

72. Biber N, Toklu HZ, Solakoglu S, Gultomruk M, Hakan T, et al. (2009) Cysteinyl-leukotriene receptor antagonist montelukast decreases blood-brain barrier permeability but does not prevent oedema formation in traumatic brain injury. Brain Inj 23(6): 577-584.

73. Thal SC, Neuhaus W (2014) The blood-brain barrier as a target in traumatic brain injury treatment. Arch Med Res 45(8): 698-710.

74. Farias S, Frey LC, Murphy RC, Heidenreich KA (2009) Injury-Related Production of Cysteinyl Leukotrienes Contributes to Brain Damage following Experimental Traumatic Brain Injury. J Neurotrauma 26(11): 1977-1986.

75. Yu GL, Wei EQ, Zhang SH, Xu HM, Chu LS, et al. (2005) Montelukast, a Cysteinyl Leukotriene Receptor-1 Antagonist, Dose- and Time Dependently Protects against Focal Cerebral Ischemia in Mice. Pharmacology 73(1): 31-40.

76. Capra V (2003) Molecular and functional aspects of human cysteinyl leukotriene receptors. Pharmacol Res 50(1):1-11.

77. https://medlineplus.gov/druginfo/meds/a600014.html.

\section{Your next submission with Juniper Publishers} will reach you the below assets

- Quality Editorial service

- Swift Peer Review

- Reprints availability

- E-prints Service

- Manuscript Podcast for convenient understanding

- Global attainment for your research

- Manuscript accessibility in different formats

(Pdf, E-pub, Full Text, Audio)

- Unceasing customer service

Track the below URL for one-step submission

https://juniperpublishers.com/online-submission.php 